\title{
Creating conditions for student success on a two-year accelerated degree
}

\author{
Poppy Frances Gibson, Sharon Perera, Robert Morgan, Bonnie Kerr \\ University of Greenwich
}

\begin{abstract}
Two-year degrees are intensive degree programmes that offer increased flexibility in Higher Education (HE) and are becoming a more appealing option for many students seeking HE study (Baty, 2017; Cabral and Lambirth, 2017), but, with lower entry requirements, are students undertaking a degree when unequipped and unprepared for the challenges that accelerated study presents?
\end{abstract}

This opinion piece focuses on the two-year BA in Primary Education and details a collaborative pilot project offered by the Faculty of Education and Health and Information and Library Services. The course uses an innovative framework that embeds academic skills in the taught programme to help students to manage better the challenges that the accelerated degree brings. Academic and information literacy skills are integrated into the subject curriculum to support students with their studies and also to enhance their abilities and build lasting confidence through employability and citizenship skills.

Findings from studies into the wellbeing of first-year students (Boni et al., 2018) show that, when students are academically and emotionally supported, we can see improved 'performance, motivation, optimism, and empathy' (Boni et al., op.cit., p.85). It is essential that $\mathrm{HE}$ institutions consider support strategies to engage students in active participation and successful completion of their degree programmes and this is of particular importance on a two-year accelerated programme, where levels of anxiety and stress may be higher, because of the necessary pace of progress. Students, owing to self-doubt, may also suffer from 'Imposter Syndrome' (IS) and educators must recognise that this feeling may be present if they are to help dissolve it.

This paper will essentially outline four potential strategies to be considered for deployment on other cross-faculty accelerated programmes.

Two-year degrees are intensive degree programmes offering increased flexibility in Higher Education $(\mathrm{HE})$ and are becoming a more appealing option for many students seeking $\mathrm{HE}$ study (Baty, 2017). There is a saying that one cannot 'fit a quart into a pint pot' and yet a student registering for a two-year degree is being asked to fit 360 credits into twenty-four months, compared to thirty-six months for a traditional three-year undergraduate degree. The advantages seem obvious, in that a student can have a degree at two-thirds of the price (Kitchener, 2017) but the disadvantages are not only, seemingly, related to time, but also to the academic demands made on the student within that time. In a report by Huxley et al. (2017), there is recognition of the additional academic demands that accelerated study places on students, particularly those who come to HE study from non-traditional academic routes and who are considered less prepared for academic study. To address this concern, many institutions identified in the report interviewed applicants before accepting them on 
accelerated programmes, as is the practice with such professional programmes as teacher training. With significantly larger cohorts than those identified in the report, however, interviewing applicants is not practical. Without this mechanism to identify student suitability at the University of Greenwich, the question is raised as to how best to support those students who may struggle to cope with the demands of accelerated study. The authors of this paper, therefore, recognise that additional support is needed if students are to cope with the heavy workload and pace of delivery and thus to achieve the time needed for their research and for the development of their academic skills.

The lurking 'Imposter Syndrome' (IS) may also hamper students' performances during their study for their degree. IS is essentially the fear of being exposed as a fraud; students fear that they are not adequately able to perform a delegated role or that they lack the required skills and knowledge (Coombes and Gibson, 2018). IS must therefore be considered as a factor behind reduced student achievement, owing to its links with anxiety and depression. Findings from studies into the wellbeing of first-year students show that, when students are academically and emotionally supported, we can see improved "performance, motivation, optimism, and empathy" (Boni et al., 2018, p.85). It is essential that HE institutions consider support strategies to engage students in active participation and to help them to complete their degree programmes successfully; this is of particular importance to students on a twoyear accelerated programme, where levels of anxiety and stress may be higher, on account of the necessary pace of progress.

An ambitious collaborative pilot project (offered by the Faculty of Education and Health and Information and Library Services, at the University of Greenwich), to embed academic skills into the two-year BA in Primary Education taught programme, presents, for the Faculty, a new way of collaborating with the University's library services. It aims to help students to manage better the challenges of an accelerated degree. Academic and information literacy skills are integrated into the subject curriculum to support students with their studies and also to enhance their abilities and build lasting confidence through employability and citizenship skills.

The concept of embedding skills within the curriculum is not a new one - the phrase was first coined in 2004 to refer to situating a librarian physically within a group in order to experience and observe the daily life of that group (Dewey, 2004). Today, this concept has moved on and 'embedding', in its purest form, involves interweaving academic skills within the course curriculum (Dewey, op.cit., cited in Shulte, 2012). Such an approach is quite unlike the old, librarian-taught, generic (or 'bolt-on') session - the "one-shot traditional model' (Hoffman et al., 2017); the "quick fix" (McWilliams and Allan, 2014) - which smacked of remedial skills sessions.

The collaboratively-delivered Accelerated Degree still relies on an embedded librarian, but now that role has been enhanced. A skills tutor is also in place, to provide a wider range of skills support, including academic writing skills. The pilot evolved from previous collaborations between the Faculty and colleagues from the Academic Support Team in Library Services. Academic Support staff ran workshops at key periods during the year to help students prepare for exams and assignments. The students participating in these interventions reported favourably that the sessions had helped them to increase their knowledge and confidence and to develop important academic skills. 
This year (2018-19), a more proactive approach, based on previous experiences, is being undertaken to shape the course so that it addresses any skills gaps that students may still have at the point of their learning the subject content.

Four strategies - expanded upon below - that the authors of this paper deem vital for student success are: accessibility to students of the Information and Library Services team when they need help with accessing materials; dialogue and feedback on academic progression; timely delivery of academic skills support; and - perhaps the most important connection provided through this pilot - the collaboration between academics and support staff in planning and delivery.

\section{These four strategies are outlined below:}

\section{- Accessibility to students and accessing materials}

By providing, through timetabled sessions, more frequent access to the Information and Library Services team, students can feel more able to contact the team for support during the academic year. Also, for students in HE, the information journey has significantly evolved over recent decades (Gibson and Smith, 2018). It is important for educators to ensure that students do not suffer from information overload when searching for materials.

\section{- Dialogue and feedback on academic progression}

Sessions that involve team-teaching between the academic and Information and Library Services team allow for more detailed dialogue and feedback to students, via the medium of appropriate writing tasks and activities. Such an approach may also be seen to counter Imposter Syndrome, because progress can be shared and students can recognise that they are developing their knowledge and skills (Coombes and Gibson, 2018).

\section{- Timely delivery of academic skills support}

Academic and information literacy skills should always be situated within a disciplinary context (Biggs, 1996; Wingate, 2006). Students are better able to understand and develop academic skills when these are taught alongside their learning, rather than in generic skills workshops offered in the library. For example, students are better able to understand how to do keyword searches or be able to discriminate between being descriptive or analytical; when these concepts are taught at the time they are beginning to prepare to write their assignments, or when they have received their marked essays.

\section{- Collaboration between academics and support staff: planning and delivery}

Underlying all three strategies shared so far, the main innovation of the pilot involves several sessions to be co-taught between the academic lecturers and the Academic Support Team in Library Services across the academic year. This ensures consistency between methods and strategies for searching and finding information. Team-teaching also allows for the culmination of skills, knowledge and experience from different members of staff, in order to help to create conditions for student success. 
To conclude, it is through collaboration between staff and students that conditions for student success may be created, and that Imposter Syndrome may be combated. As this innovative pilot evolves over the coming academic year, student progression and attainment data will show if it has been successful. The authors hope to publish future research papers about, and evaluations of, the pilot in order to share, with other educators, best practice in creating conditions for student success.

\section{Reference list}

Baty, P. (2017) 'Two-year degrees: Twitter responds to UK fast-track degree plans.' Times Higher Education. Available at: https://www.timeshighereducation.com/blog/two-yeardegrees-twitter-responds-uk-fast-track-degree-plans (Accessed: 3 September 2018).

Biggs, J. (1996) 'Enhancing teaching through constructive alignment.' Higher Education, 32(3), 347-364. Available at: https://link.springer.com/article/10.1007/BF00138871 (Accessed: 8 September 2018).

Cabral, A. and Lambirth, A. (2017) 'Accelerated degrees in education: a new profile, alternative access to teaching or part of a re-tooling process?' Journal of Further and Higher Education, 42(6). Available at:

https://www.tandfonline.com/doi/full/10.1080/0309877X.2017.1311995 (Accessed: 3

September 2018).

Coombes, S. and Gibson, P. (2018) 'Feeling like a fraud: Engaging Students with Imposter Syndrome.' Higher Education Journal of Teaching and Learning, 9(2). Available at: http://hejlt.org/article/feeling-like-a-fraud-engaging-students-with-impostersyndrome/_(Accessed: 3 September 2018).

Dewey, B.I. (2004) 'The Embedded Librarian; Strategic Campus Collaborations.' Resource Sharing and Information Networks (The Haworth Information Press), 17(1/2), 517. Available at: http://www.haworthpress.com/web/RSIN (Accessed: 3 September 2018).

Gibson, P. and Smith, S. (2018) 'Digital literacies: preparing pupils and students for their information journey.' Information and Learning Science, 119 (12). Available at: https://www.emeraldinsight.com/doi/abs/10.1108/ILS-07-20180059?fullSc=1\&journalCode=ils (Accessed: 3 September 2018).

Hoffman, N., Beatty, S., Feng, P. and Lee, J. (2017) 'Teaching research skills through embedded librarianship.' Reference Services Review, 45(2), 211-226. Available at: https://doi.org/10.1108/RSR-07-2016-0045 (Accessed: 3 September 2018).

Huxley, C., Green, M., Swift, S. and Pollard, E. (2017) Accelerated Degrees in Higher Education: A case study report. Available at: https://assets.publishing.service.gov.uk/government/uploads/system/uploads/attachment data/file/595638/Accelerated Degrees Case Study Report.pdf (Accessed: 3 September 2018). 
McWilliams, R. and Allan, Q. (2014) ‘Embedding Academic Literacy Skills: Towards a Best Practice Model.' Journal of University Teaching and Learning Practice, 11(3), Article 8. Available at: http://ro.uow.edu.au/jutlp/vol11/iss3/8 (Accessed: 3 September 2018).

Kitchener, I. (2017) 'Are accelerated degrees the future for Higher Education?' Compass: Journal of Learning and Teaching, 10(3). Available at:

https://journals.gre.ac.uk/index.php/compass/article/view/569 (Accessed: 3 September 2018).

Schulte, S.J. (2012) 'Embedded academic librarianship: A Review of the Literature.' Evidence Based Library and Information Practice. Available at:

https://doi.org/10.18438/B8M60D (Accessed: 3 September 2018).

University of Greenwich, Library Services (2018) 'Curious, Informed, Accomplished.' Available at: https://www.gre.ac.uk/articles/academicskills/curious-informed-accomplished (Accessed: 3 September 2018).

Wingate, U. (2006) 'Doing away with study skills'. Teaching in Higher Education, 11(4), 457469. (Accessed: 3 September 2018). 